\title{
Removal of Antimony and Bismuth from Copper Electrorefining Electrolyte: Part II-An Investigation of Two Proprietary Solvent Extraction Extractants
}

\begin{abstract}
ANDREW ARTZER, ${ }^{1}$ MICHAEL MOATS ${ }^{1},{ }^{1,3}$ and JACK BENDER ${ }^{2}$
1.-Materials Research Center, Missouri S\&T, Rolla, MO 65401, USA. 2.-BASF Mining Chemicals, Tucson, AZ 85706, USA. 3.—e-mail: moatsm@mst.edu

Antimony and bismuth recovery from copper electrorefining electrolyte could reduce the impacts of these problem elements and produce a new primary source for them. Two proprietary phosphonic acid ester extractants were examined (REX-1 and REX-2) for the removal of antimony and bismuth from copper electrorefining electrolytes. Experimentation included shakeout and break tests to determine the basic parameters for the extractants in terms of maximum loading, break times, and extraction and stripping efficiency. Five permutations of extractant mixtures (100 wt.\% REX-1 and 25 wt. $\%, 50$ wt.\%, 75 wt.\% and 100 wt.\% REX-2) were studied. It was determined that REX-2 was able to extract $\mathrm{Sb}$ and $\mathrm{Bi}$ from the electrolyte, but required some mixture with REX-1 to better facilitate stripping with $400 \mathrm{~g} / \mathrm{L}$ sulfuric acid. The laboratory electrorefining electrolyte containing glue had faster disengagement times than a synthetic solution without glue.
\end{abstract}

\section{INTRODUCTION}

As discussed in our review, antimony and bismuth in copper electrorefining electrolyte can cause operational problems. ${ }^{1}$ The traditional method for removing antimony and bismuth involves putting a bleed stream of electrolyte through liberator cells (or electrowinning cells). Liberators can remove most of the antimony and bismuth by electrodeposition; however, this process has several drawbacks. The copper electrodeposits produced during antimony and bismuth removal contain arsenic, making the material hazardous. The deposits are recycled to a smelter with the majority of the group 15 elements eventually returning to the refinery in future anodes. Liberators are also costly to operate because of labor requirements and high electrical energy consumption, and they can produce hazardous gases. $^{2-4}$

Because of these drawbacks, many refineries have examined alternative ways to remove antimony and bismuth from electrolyte. Solvent extraction (SX), ${ }^{1,5,6}$ molecular recognition technology, ${ }^{7,8}$ carbon adsorption ${ }^{9,10}$ and ion exchange (IX) ${ }^{11,12}$ have been the most researched processes. IX columns have been installed at several copper electrorefineries. IX is typically preferred over SX when the ion concentration to be removed is $<0.5$ $\mathrm{g} / \mathrm{L}$ in the aqueous phase (as is the case for $\mathrm{Sb}$ and $\mathrm{Bi}$ in commercial electrolytes). ${ }^{11,13}$ Refineries, however, use $\mathrm{HCl}$ to elute antimony and bismuth from the resins ${ }^{11,13}$ which can potentially cause upsets if the high chloride content solutions enter the electrorefining electrolyte. Furthermore, most refineries do not recover $\mathrm{Sb}$ and $\mathrm{Bi}$ as a salable product. Therefore, a method that removes $\mathrm{Sb}$ and $\mathrm{Bi}$ from electrolyte, uses a sulfuric acid stripping agent and produces a salable product could be useful to copper electrorefineries.

BASF has recently developed a set of SX extractants designed for antimony and bismuth removal from electrolyte that can be stripped using sulfuric acid without regeneration. ${ }^{1}$ The proprietary reagents (REX-1 and REX-2) are phosphonic acid esters that extract by forming ionic complexes with the ions of interest. Phosphonic acid is characterized by a phosphorus atom with one organic bond, two hydroxides and one double-bonded oxygen (Fig. 1). The phosphonic acid functional group was described by Sevrain et al. ${ }^{14}$ Phosphonic acid ester extractants have previously been examined in the removal of $\mathrm{Co}, \mathrm{Ni}$ and $\mathrm{Mn}$ from sulfate solutions. ${ }^{15,16}$ If these 


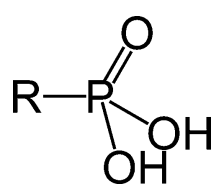

Fig. 1. The structure of a phosphonic acid functional group.

reagents could be used to recover bismuth and antimony as salable products, they could assist in improving the sustainability of the bismuth and antimony supply chains.

\section{PROCEDURE}

\section{Organic Solution}

Two phosphonic acid ester extractants (REX-1 and REX-2) were provided by BASF Mining Chemicals. Five mixtures of the extractants were examined (100 wt.\% REX-1 and 25 wt. $\%, 50$ wt.\%, 75 wt.\% and 100 wt.\% REX-2). Organic solutions used for solvent extraction experiments were created by mixing $100 \mathrm{~g} / \mathrm{L}$ of the extractant mixture into Orfom SX-12 diluent (a Chevron Phillips product).

\section{Aqueous Solution}

The aqueous solutions used in most of the solvent extraction experiments were electrolyte samples collected from a laboratory-scale copper electrorefining cell. The cell was operated in a manner similar to a stripper cell (a.k.a. produced starter sheets) in an industrial operation, including the addition of glue. The anodes were commercial copper anode samples from a North American refinery. Details about the laboratory-scale electrorefining cell and its operation were presented by Laforest. ${ }^{17}$ Electrolyte samples from a laboratory electrorefining cell were used to more accurately reflect the performance of the extractants in an electrorefining plant. For convenience, these electrolyte samples, used within an hour of collection, will be referred to as "live" electrolyte for the remainder of this manuscript. Each individual "live" sample is denoted with the day of operation that it was collected. The day number refers to the number of days after a set of commercial anode samples was inserted into the laboratory cell. Electrolyte samples used after being stored about a month at room temperature will be referred to as "aged" electrolyte. The storage of electrolyte can fundamentally change the electrolyte (decomposition of glue, precipitation of copper or other species), so its use is noted for clarity.

Finally, synthetic electrolytes made from reagent grade chemicals were used for selected experiments. Extraction isotherms were created using synthetic electrolytes containing only sulfuric acid, copper and antimony or bismuth. To examine the effect of organics on phase disengagement time, an electrolyte (synthetic-break) was created of similar composition to the "live" electrolyte tested.

Compositions of each electrolyte used in this study are listed in Table I. The original source chemicals were potassium antimony tartrate trihydrate for antimony, $\mathrm{BiCl}_{3}$ for bismuth, $\mathrm{CuSO}_{4} \cdot 5 \mathrm{H}_{2} \mathrm{O}$ for copper and $\mathrm{As}_{2} \mathrm{O}_{3}$ for arsenic. A commercial glue provided by a North American refinery was added to the laboratory-scale refinery cell at a rate of $2.16 \mathrm{mg}$ glue per liter of electrolyte per day. In these tests, Avitone A was also added to the refinery cell, but thiourea was not.

\section{Shakeout Tests}

Shakeout tests were performed to examine extraction and stripping efficiency. A Burrell model 75 wrist action shaker with amplitude set to 7.5 was used; $15 \mathrm{~mL}$ of organic and $15 \mathrm{~mL}$ of electrolyte were placed in $30-\mathrm{mL}$ separatory funnels attached to the shaker. The funnels were rotated so they were parallel to the ground to ensure no unmixed organic or aqueous material remained at the tips of the funnels. The two phases were shaken for $30 \mathrm{~min}$ to reach equilibrium. After visual confirmation of phase disengagement, the raffinate was drained from the separatory funnel and passed through a Whatman 4 filter paper to remove organic entrainment. Organic material collected on the filter paper was returned to the funnel.

Following the extraction test, $15 \mathrm{~mL}$ of $400 \mathrm{~g} / \mathrm{L}$ sulfuric acid was added to each separatory funnel containing loaded organic. The funnel was again shaken for $30 \mathrm{~min}$. The aqueous strip product solution was collected in the same way as the raffinate in the previous step.

Shakeout tests were conducted with various electrolyte samples ("aged" or "live") and one of the five organic solutions. All the electrolyte samples were allowed to cool to room temperature before shaking to guarantee consistent temperature between tests. Fresh organic solution was used in each test.

The collected samples of raffinate and strip product were diluted with deionized (DI) water and analyzed using an iCE3300 FL atomic absorbance (AA) system. The specific dilutions were 10,000:1 for copper, 16:1 for antimony and bismuth, and 150:1 for arsenic. Due to manual dilutions, the AA measurements were found to return measurements with 1-4\% error for synthetic solutions of known concentration. This error occasionally resulted in calculated raffinate concentrations being slightly (no greater than 4\%) greater than those of the original electrolyte. Since fresh organic solutions were used in all experiments, it was assumed that the raffinate concentrations in these cases were equal to the original electrolyte. Otherwise, the concentrations reported are the average value for two experiments. 
Table I. Composition of the electrolytes used in the following experiments

\begin{tabular}{|c|c|c|c|c|c|c|}
\hline Electrolyte & Copper $(g / L)$ & Antimony (g/L) & Bismuth $(\mathbf{g} / \mathbf{L})$ & $\operatorname{Arsenic}(g / L)$ & $\operatorname{Acid}(\mathbf{g} / \mathbf{L})$ & Glue (mg/L/day) \\
\hline Aged & 51.0 & 0.098 & 0.009 & 5.35 & 147 & 2.16 \\
\hline Live (day 4) & 40.8 & 0.193 & 0.078 & 7.89 & 158.4 & 2.16 \\
\hline Live (day 14) & 45.6 & 0.179 & 0.119 & 7.88 & 140.7 & 2.16 \\
\hline Live (day 24) & 40.3 & 0.157 & 0.159 & 7.27 & 160.5 & 2.16 \\
\hline Live (day 25) & 40.2 & 0.17 & 0.16 & 7.44 & 160 & 2.16 \\
\hline Synthetic (Bi) & 43.9 & 0 & 0.049 & 0 & 170 & 0 \\
\hline Synthetic (Sb) & 42.3 & 0.178 & 0 & 0 & 170 & 0 \\
\hline Synthetic (break) & 37.7 & 0.122 & 0.228 & 5.38 & 160 & 0 \\
\hline
\end{tabular}

\section{Isotherms}

Extraction isotherms for bismuth and antimony were created using the shake out procedure. Isotherms were only made for 100 wt.\% REX-1, 100 wt.\% REX-2 and the 50/50 blend. The extractants were dissolved in Orfom SX-12 at concentrations of $100 \mathrm{~g} / \mathrm{L}$. All the extractants were tested with $1: 2$, $1: 1,2: 1,4: 1,7: 1,10: 1$ and $20: 1 \mathrm{~A} / \mathrm{O}$ ratios. However, due to the higher loading capacity of REX-2 and the 50/50 blend, they were also tested at 40:1, 60:1, 80:1 and 100:1.

The aqueous solutions used were two simplified synthetic electrolytes that resembled electrorefining electrolyte in terms of copper and acid concentrations but were simplified to isolate antimony or bismuth extraction. One synthetic electrolyte contained $\mathrm{H}_{2} \mathrm{SO}_{4}$, copper and antimony, while the other had $\mathrm{H}_{2} \mathrm{SO}_{4}$, copper and bismuth. These electrolytes are named "synthetic (Sb)" and "synthetic (Bi)," respectively, and their compositions are listed in Table I.

\section{Phase Break Tests}

Phase break experiments were conducted because of previous literature indicating that glue can cause phase separation issues. ${ }^{18,19}$ Glue is added during electrorefining as a cathode leveling agent and was present in the "live" electrolytes. Therefore, break times were compared between "live" electrolyte and a synthetic electrolyte that did not contain glue. Both extraction and stripping break tests were performed, so the aqueous material consisted of an electrolyte (Table I) or a $400 \mathrm{~g} / \mathrm{L} \mathrm{H}_{2} \mathrm{SO}_{4}$ stripping solution (for extraction and stripping, respectively). Disengagement times were determined for organic solutions with only REX-1 or REX-2. Emulsion phase continuity was also examined.

These experiments were conducted in a $1000-\mathrm{mL}$ glass beaker with stainless steel baffles; $200 \mathrm{~mL}$ of aqueous and $200 \mathrm{~mL}$ of organic were mixed together using a Cole-Parmer Ultra-compact Digital Mixer (model no. 50006-01) with a 1.25-inch-diameter plastic impeller at $1750 \mathrm{rpm}$. The emulsion was mixed for $30 \mathrm{~s}$ after the mixer reached full speed. The impeller was removed after it had completely stopped. Disengagement time was measured from when the mixer was turned off until a clear visual boundary had formed between the two phases. The reported values are the average of two or three experiments.

\section{RESULTS AND DISCUSSION}

\section{Extraction and Stripping Efficiencies}

Extraction efficiencies for $\mathrm{Bi}, \mathrm{Sb}, \mathrm{Cu}$ and $\mathrm{As}$ using fresh organic and an $\mathrm{A} / \mathrm{O}$ ratio of $1: 1$ are shown in Fig. 2. These data indicate that increasing the percentage of REX-2 in the extractant mixture increased the percentage of antimony and bismuth extracted. The 100 wt.\% REX-2 extractant removed $85-95 \%$ of the antimony and $60-70 \%$ of the bismuth in the "live" electrolyte samples. Thus, REX-2 appears to be a better extractant than REX-1 for antimony and bismuth. No synergistic effect was observed between REX-1 and REX-2 on extraction efficiency. While extraction of $\mathrm{Cu}$ and As was small in terms of percentages (generally $<10 \%$ ), the starting concentrations of these elements are one or two orders of magnitude higher than $\mathrm{Sb}$ and $\mathrm{Bi}$. Therefore, their extraction is not insignificant. As the aged electrolyte produced similar results as the "live" electrolyte, it appears that electrolyte can be stored and treated as needed.

Stripping efficiencies for the loaded organics produced in the extraction efficiency experiments are shown in Fig. 3a, b, c, and d. The stripping data in terms of percentages are more variable than the extraction data because of the smaller concentrations involved and the accuracy of the analysis method used (manual dilution + AA). Even so, a synergistic effect of REX-1 on the ability to strip Sb from REX-2 was indicated. The presence of REX-1 allowed for a higher percentage of the loaded Sb to be stripped with $400 \mathrm{~g} / \mathrm{L}$ sulfuric acid. Bi stripping was also improved by the addition of REX-1 to REX2. The stripping efficiencies indicate that some $\mathrm{Sb}$ and $\mathrm{Bi}$ remain on the extractant after stripping. The stripping efficiencies for $\mathrm{Cu}$ and As were extremely variable. This variation cannot be explained at this time, but may be related to the large dilution factors used prior to analysis.

Combining the extraction and stripping data, the overall removal efficiency for each shakeout test 
(a) 100

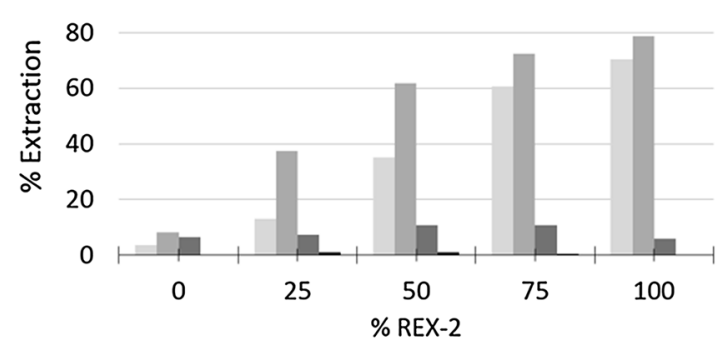

(c) 100

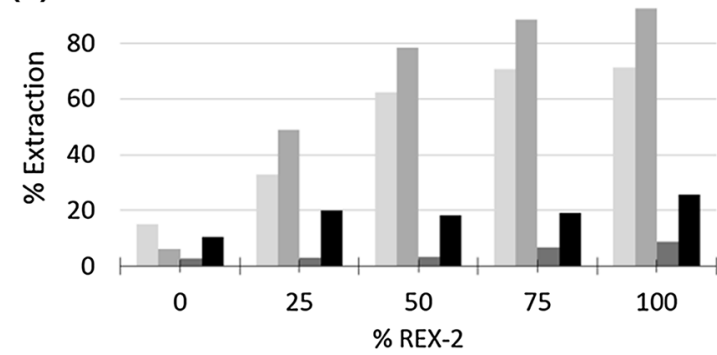

(b) 100

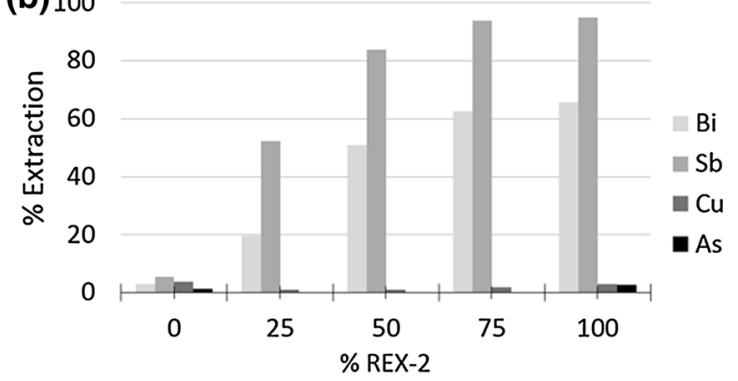

(d) 100

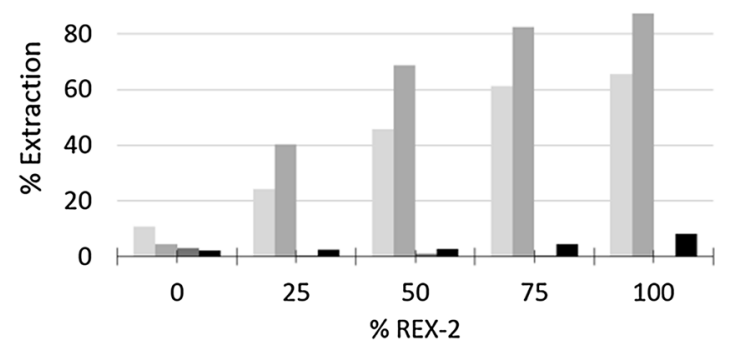

Fig. 2. Extraction efficiency for REX-1 and REX-2 mixtures. Tested in (a) aged electrolyte, (b) live day 4 electrolyte, (c) live day 14 electrolyte, (d) live day 24 electrolyte. See Table I for electrolyte compositions. A:O ratio = 1:1 for all experiments.

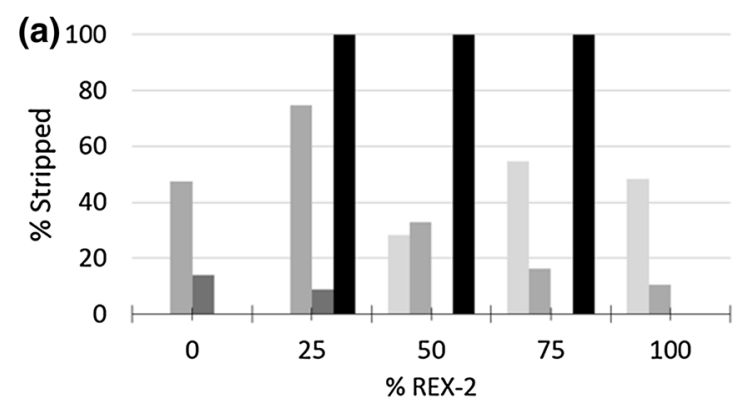

(c) 120

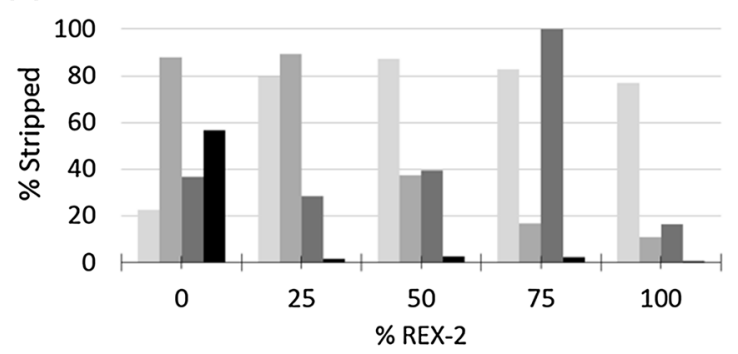

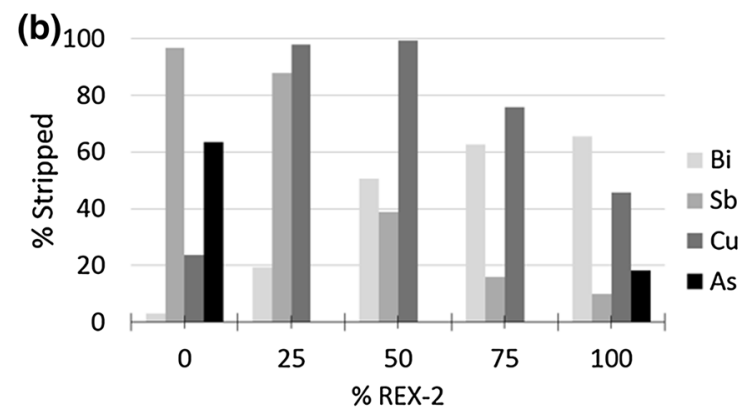

(d) 100

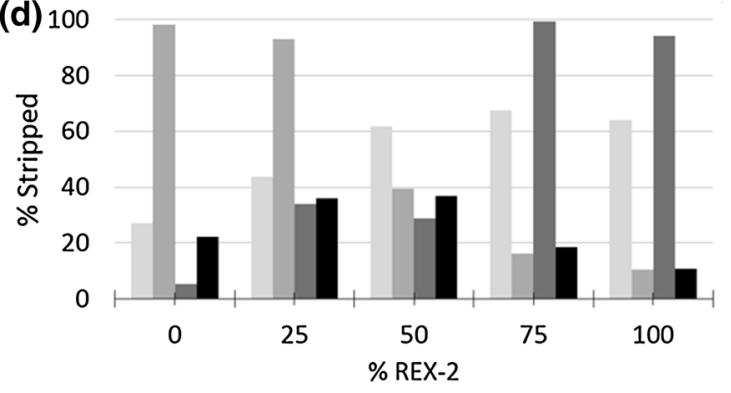

Fig. 3. Stripping efficiency of the tested solvents. Tested in (a) aged electrolyte, (b) live day 4 electrolyte, (c) live day 14 electrolyte, (d) live day 24 electrolyte. (d) was performed for $24 \mathrm{~h}$. See Table I for electrolyte compositions. A:O ratio = 1:1 for all experiments.

was calculated (Fig. 4a, b, c, and d). For antimony, the higher percentage REX-2 solutions exhibited superior extraction efficiency, but poor stripping efficiencies. Thus, the antimony removal efficiencies for 75 wt.\% and 100 wt.\% REX-2 solutions were $<15 \%$. The 25 wt.\% REX-2 solution demonstrated the highest $\mathrm{Sb}$ removal efficiency because of its better stripping efficiency. Thus, a mixture of REX-1 and REX-2 provides synergistic behavior by REX-1 improving strippability and REX-2 increasing extraction.
The removal efficiency for bismuth presents a different scenario. Bismuth removal is maximized at high wt.\% REX-2 solutions. The addition of small amounts of REX-1 may improve removal efficiency, but high concentrations of REX-1 appear to be detrimental to bismuth removal.

The ability to tailor the performance of the mixed extractant system to preferentially remove more $\mathrm{Sb}$ or $\mathrm{Bi}$ could be utilized by copper refineries. For example, a 25/75 REX-1/REX-2 mixture could be preferred by a refinery with high $\mathrm{Sb}$, low $\mathrm{Bi}$ anodes. 


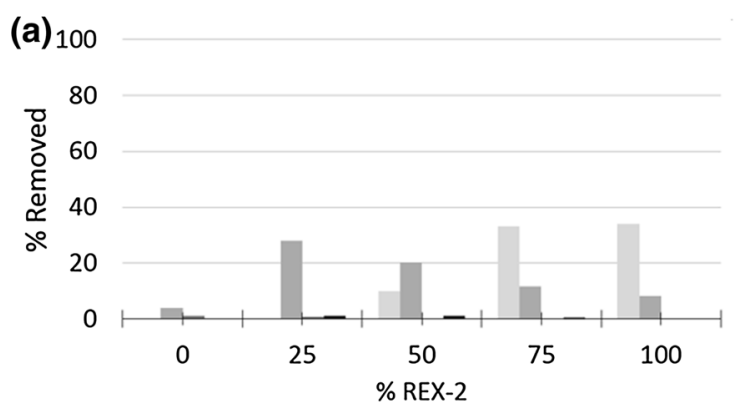

(c) 100

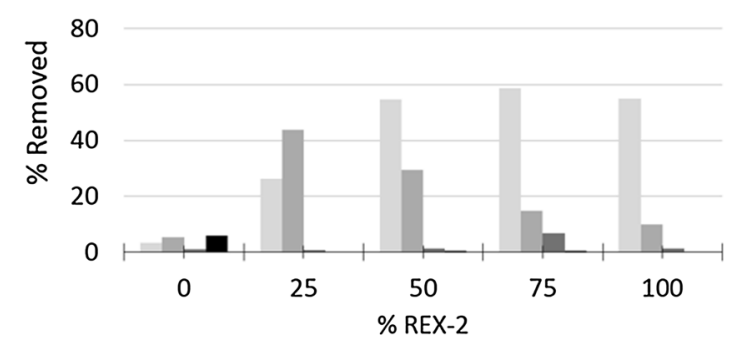

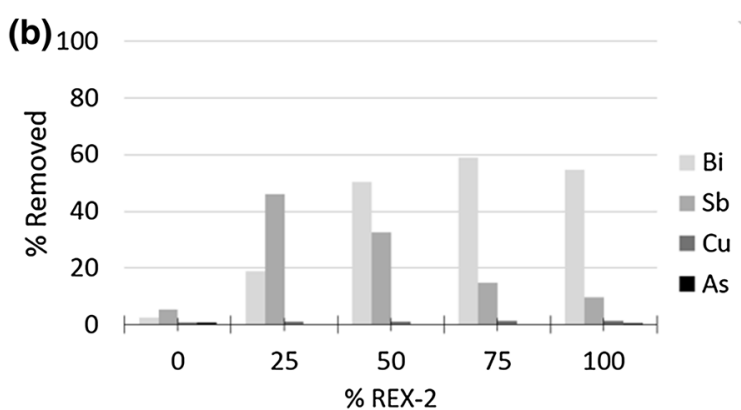

(d) 100

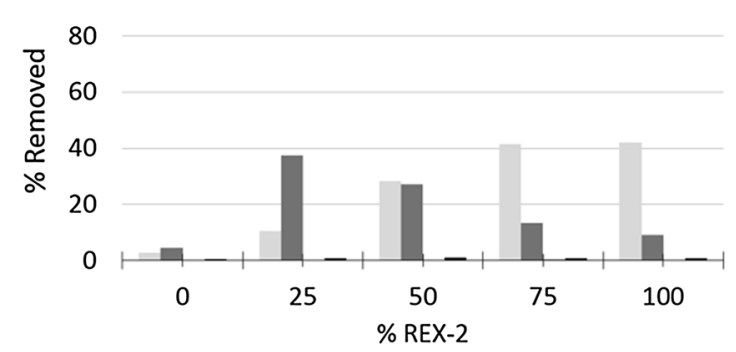

Fig. 4. Removal percentages of the tested solvents. Tested in (a) aged electrolyte, (b) live day 4 electrolyte, (c) live day 14 electrolyte, (d) live day 24 electrolyte. See Table I for electrolyte compositions.

On the other hand, a 75/25 REX-1/REX-2 mixture might be favored for anodes with high $\mathrm{Bi}$ and low $\mathrm{Sb}$.

Typically, high removal efficiencies are desired for solvent extraction systems. With the current extractant system, high removal rates are unnecessary. The purpose of the proposed system is to remove impurities from electrolyte. Thus, small removal efficiencies can be designed into a potentially effective bleed treatment system.

The removal efficiencies for copper and arsenic were low with all values $<10 \%$. This is a highly encouraging result as it indicates the potential to produce a strip product with low concentrations of copper and arsenic. Obviously more testing is needed, and a mini-laboratory-scale pilot plant test is planned for the near future.

\section{Isotherms}

To understand further the loading capabilities of these extractants, extraction isotherms for $\mathrm{Sb}$ and Bi on 100 wt.\% REX-1, 50 wt.\% REX-2 and 100 wt.\% REX-2 were generated using synthetic electrolytes and different $\mathrm{A} / \mathrm{O}$ ratios. The extraction isotherms for $\mathrm{Bi}$ are presented in Fig. 5. As expected from the shakeout experiments, REX-1 alone does not extract bismuth to any appreciable extent. REX-2 alone demonstrated the ability to extract $\mathrm{Bi}$. A loading of $0.34 \mathrm{~g} \mathrm{Bi} / \mathrm{L}$ for $100 \mathrm{~g} \mathrm{REX}-2$ per liter in the organic phase was achieved at an A/O ratio of 100:1 (0.05 g/ $\mathrm{L} \mathrm{Bi}$ in the feed aqueous phase). The $50 \mathrm{wt} . \% \mathrm{REX}-2$ achieved a maximum loading around $0.43 \mathrm{~g} \mathrm{Bi} / \mathrm{L}$. It is not clear from these tests that the maximum bismuth loading was reached in Fig. $5 \mathrm{~b}$ and c.

The antimony extraction isotherms also revealed that REX-1 did not extract Sb significantly (Fig. 6a).
It appears that the maximum loading of $\mathrm{Sb}$ for 50 wt.\% and 100 wt.\% REX-2 mixtures (Fig. $6 \mathrm{~b}$ and c) was found. The $100 \mathrm{~g} / \mathrm{L} 100$ wt.\% REX-2 solution appears to have a maximum loading near $7 \mathrm{~g}-\mathrm{Sb} / \mathrm{L}-$ organic. The 50 wt.\% REX-2 solution exhibited a maximum concentration of $2 \mathrm{~g}$-Sb/L-organic.

\section{Phase Break Time}

The final part of this investigation was to examine phase disengagement times (PDTs). Based on previous literature ${ }^{18,19}$ the effect of glue in electrolyte on solvent extraction was concerning. The conditions and results of the PDTs are shown in Table II. The results were analyzed by examining the differences in mean for each parameter in the factorial design and examining the $p$ values for the main parameters (Table III). Phase continuity (organic or aqueous), stage (extraction or stripping) and electrolyte type ("live" or synthetic) affected the mean time for phase disengagement based on $p$ values $<0.05$ as shown in Table III. The stripping step (using $400 \mathrm{~g} / \mathrm{L} \mathrm{H}_{2} \mathrm{SO}_{4}$ ) had a longer break time than extraction (with $180 \mathrm{~g} / \mathrm{L} \mathrm{H}_{2} \mathrm{SO}_{4}$ ), which was likely caused by the increase in the viscosity of the aqueous phase. Organic continuity produced longer separation times than aqueous continuity. Finally, synthetic electrolyte (without glue) had longer disengagement times than "live" electrolyte (with glue).

While the presence of glue in the "live" electrolyte did have a statistical effect, the observed effect was the opposite of what was expected based on previous reports. ${ }^{18,19}$ Glue was not the only organic in the solution at the time of testing (Avitone $\mathrm{A}$ and tartrate were also present in the "live" and synthetic electrolytes, respectively), which could be a 
Removal of Antimony and Bismuth from Copper Electrorefining Electrolyte: Part II-An Investigation of Two Proprietary Solvent Extraction Extractants

(a)

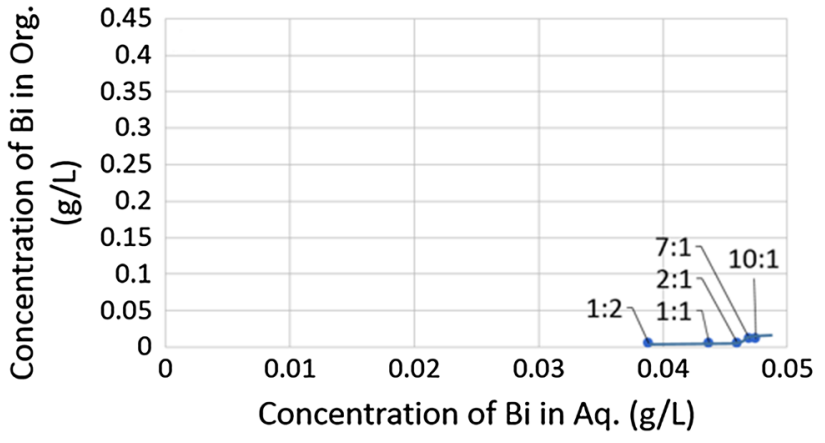

(b)

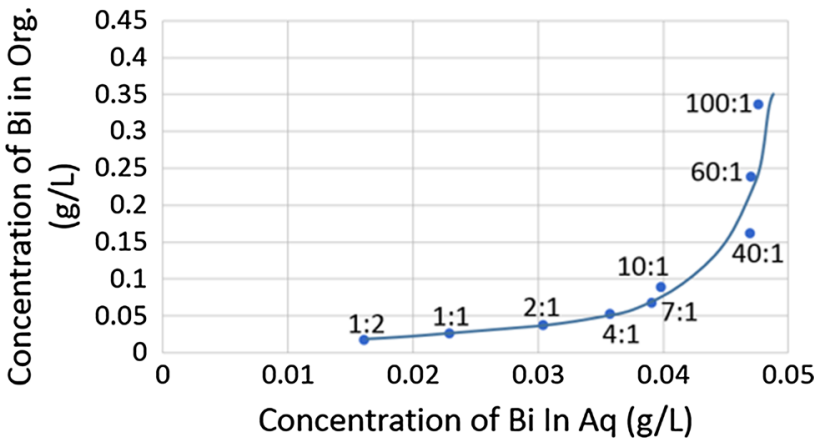

(c)

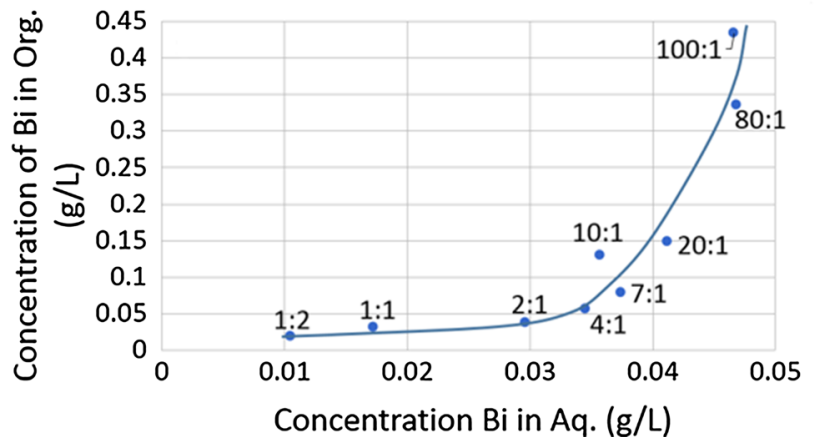

Fig. 5. Extraction isotherms for bismuth in (a) REX-1, (b) 50 wt.\% REX-2, and (c) REX-2 Performed with synthetic (Bi) electrolyte. See Table I for electrolyte compositions.

(a)

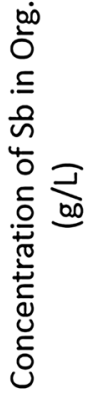

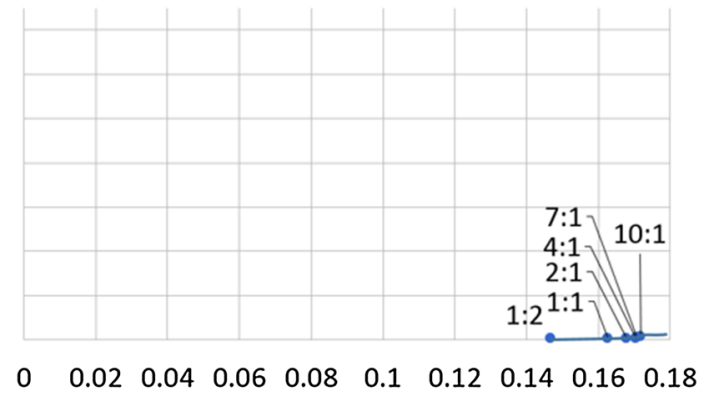

Concentration of $\mathrm{Sb}$ in Aq. (g/L) (b)

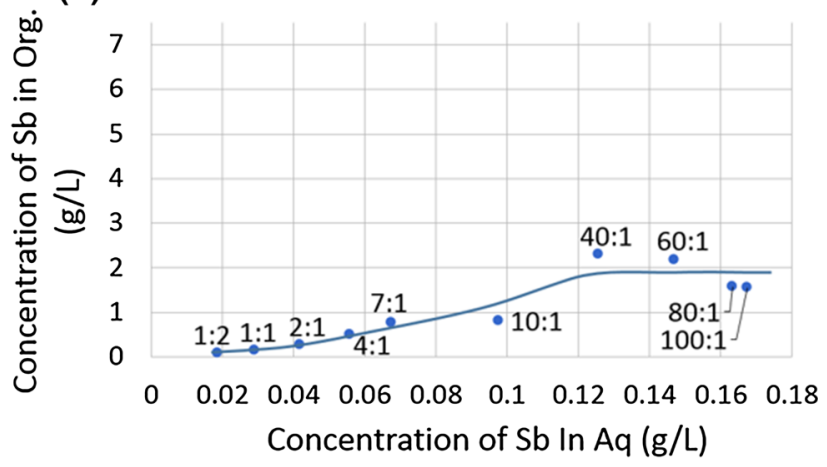

(c)

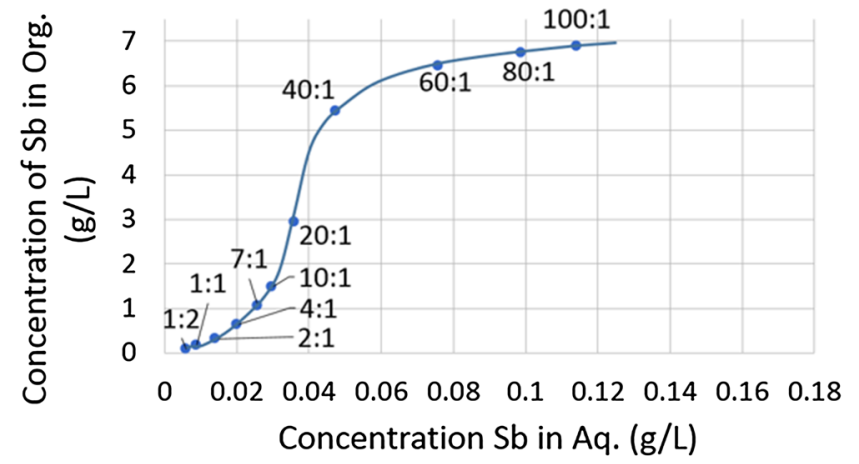

Fig. 6. Extraction isotherms for antimony in (a) REX-1, (b) 50 wt.\% REX-2, and (c) REX-2. Performed with synthetic (Sb) electrolyte. See Table I for electrolyte compositions. 
Table II. Average break times for aqueous and organic continuous phases. Performed with live (day 25) electrolyte (Table I)

\begin{tabular}{|c|c|c|c|c|}
\hline \multirow[b]{2}{*}{$\begin{array}{l}\text { Extractant } \\
\text { percentage }\end{array}$} & \multicolumn{2}{|c|}{ Aqueous continuous } & \multicolumn{2}{|c|}{ Organic continuous } \\
\hline & $\begin{array}{c}\text { "Live" electrolyte } \\
\text { (s) }\end{array}$ & $\begin{array}{c}\text { Synthetic electrolyte } \\
\text { (s) }\end{array}$ & $\begin{array}{c}\text { "Live" electrolyte } \\
\text { (s) }\end{array}$ & $\begin{array}{l}\text { Synthetic electrolyte } \\
\text { (s) }\end{array}$ \\
\hline 100\% REX-1: extract & 59 & 69 & 71 & 94 \\
\hline 100\% REX-1: strip & 123 & 113 & 164 & 236 \\
\hline 100\% REX-2: extract & 53 & 50 & 104 & 221 \\
\hline 100\% REX-2: strip & 66 & 77 & 87 & 199 \\
\hline
\end{tabular}

Table III. Structure and results for the fractional factorial statistical analysis performed on the phase break data

\begin{tabular}{|c|c|c|c|c|}
\hline Factor & $\mathbf{A}$ & $\mathbf{B}$ & $\mathbf{C}$ & D \\
\hline Parameter & Continuity & Electrolyte & Stage & REX \\
\hline Low value & Aqueous & "Live" & Strip & 1 \\
\hline High value & Organic & Synthetic & Extract & 2 \\
\hline $\bar{y}$ (low) & 80.7 & 96.7 & 149 & 119 \\
\hline $\bar{y}$ (high) & 148 & 131 & 89.9 & 109 \\
\hline $\mathrm{I} \Delta \mathrm{I}$ & 67.1 & 34.3 & 59.1 & 10 \\
\hline$p$ & $<0.001$ & 0.009 & 0.003 & 0.416 \\
\hline
\end{tabular}

reason for the discrepancy. Additionally, reagent chemicals were not purified before testing, and organic impurities could have also been present in the synthetic solutions. There is a plan for further testing of these extractants in a laboratory-scale extraction circuit. Break times and crud formation will continue to be monitored to verify these results.

Interactions between parameters were examined on PDTs. From a statistical standpoint, two interactions (1, phase continuity and electrolyte type; 2 , stage and REX) were found to be as significant as electrolyte type. The authors are not sure if they believe these interactions are real. More research would be needed to confirm their validity.

\section{CONCLUSION}

This investigation of two proprietary phosphonic acid ester extractants for the recovery of antimony and bismuth from copper electrorefining electrolyte revealed:

1. Extraction of $\mathrm{Sb}$ and $\mathrm{Bi}$ increased with increasing weight percent of REX-2 in the organic solution. REX-1 exhibited only a small ability to extract $\mathrm{Sb}$ and $\mathrm{Bi}$ by itself.

2. Stripping of $\mathrm{Sb}$ and $\mathrm{Bi}$ from REX-2 was assisted by the addition of REX-1.

3. The highest removal efficiencies were achieved with mixtures of REX-1 and REX-2. Higher REX-2 content mixtures exhibited the highest removal efficiencies for bismuth. Lower REX-2 content mixtures demonstrated larger removals of antimony.

4. Phase disengagement times were influenced by phase continuity, electrolyte used ("live" versus synthetic) and the stage (extraction versus stripping). The effect of glue in the live electrolyte was statistically significant, but showed a reduced phase separation time, which was not expected. All of the phase disengagement data indicate that phase separation in a commercial SX settler should be achievable.

While these extractants are fully capable of removing $\mathrm{Sb}$ and $\mathrm{Bi}$ from copper electrorefining electrolytes, they also extract small percentages of $\mathrm{Cu}$ and As. Though the percentages are small, the concentrations of $\mathrm{Cu}$ and $\mathrm{As}$ in the electrolyte are much higher than $\mathrm{Bi}$ and $\mathrm{Sb}$. If $\mathrm{Sb}$ and $\mathrm{Bi}$ are desired as a saleable product, additional purification steps or possibly organic scrubbing will be needed to separate $\mathrm{Sb}$ and $\mathrm{Bi}$ from $\mathrm{Cu}$ and $\mathrm{As}$. If not, all the elements could be precipitated together and returned to the smelter. While returning the materials to the smelter would eliminate the possibility of $\mathrm{Bi}$ and $\mathrm{Sb}$ recovery, removal of $\mathrm{Bi}$ and $\mathrm{Sb}$ from the refinery without the use of liberator cells or IX with $\mathrm{HCl}$ elution could be advantageous.

Additional batch tests and a laboratory-scale solvent extraction circuit will be operated to understand better the removal and recovery of antimony and bismuth from copper electrorefining electrolyte. Special attention will be paid to the deportment of copper and arsenic, phase disengagement and the formation of any crud or stable emulsions.

\section{FUNDING}

Funding was provided by BASF.

\section{REFERENCES}

1. J. Bender and N. Emmerich, in Proceedings of Copper 2016 (2016), p. 1128.

2. A.K. Biswas, W.G. Davenport, and D.W. Hopkins, Extractive Metallurgy of Copper, 2nd ed. (Oxford: Pergamon Press, 1980), pp. 310-312.

3. V. Stoyanova, K. Nedeleva, A. Saraev, L. Gerov, and V. Stoyanova, in Proceedings of Copper 2016 (2016), p. 1957. 
4. B.C. Wesstrom and O. Araujo, in Proceedings of T.T. Chen Honorary Symposium on Hydrometallurgy, Electrometallurgy and Materials Characterization (2012), p. 151.

5. S. Wang, JOM 56, 34 (2004).

6. J. Szymanowski, Miner. Process. Extr. Metall. Rev. 18, 389 (1998).

7. L. Navarro, T. Morris and W. Read, in Proceedings of Copper 2013, vol 2 (2013), p. 261.

8. R.L. Bruening, J.B. Dale, N.E. Izatt and S.R. Izatt, in 2003, Proceedings of the International Symposium on Hydrometallurgy, 5th ed., vol 1 (2003), p. 729.

9. K. Toyabe, C. Segawa, and H. Sato, Proceedings of Copper 87 (1987), p. 117.

10. I. Ruiz, G. Rios, C. Arbizu, I. Burke, U. Hanschke, in European Metallurgical Conference (2013), p. 1.

11. K. Ando and N. Tsuchida, JOM 49, 49 (1997).
12. T. Nagai, Miner. Process. Extr. Metall. Rev. 17, 143 (1997).

13. P. Navarro, J. Simpson, and F.J. Alguacil, Hydrometallurgy 53, 121 (1999).

14. C.M. Sevrain, M. Berchel, H. Couthon, and P.A. Jaffrès, Beilstein J. Org. Chem. 13, 2186 (2017).

15. J.S. Preston, Hydrometalurgy 49, 115 (1982).

16. P.E. Tsakiridis and S. Agatzini-Leonardou, J. Chem. Technol. Biotechnol. 80, 1236 (2005).

17. P. Laforest, Understanding Impurities in Copper Electrometallurgical Processes (Rolla: Missouri University of Science and Technology, 2015), pp. 41-44.

18. W.R. Hopkins, G. Eggett, and J.B. Scuffham, in International Symposium on Hydrometallurgy, 2nd ed. (1973), p. 127.

19. D.J. Readett, and C.J. Mark, in Non-ferrous Smelting Symposium (1989), p. 175. 